\title{
DEVELOPING AND TESTING A 3D CADASTRAL DATA MODEL A CASE STUDY IN AUSTRALIA
}

\author{
A. Aien*, M. Kalantari, A. Rajabifard, I. P. Williamson, D. Shojaei
}

Centre for SDIs and Land Administration (CSDILA), Dept. of Infrastructure Engineering, School of Engineering,

The University of Melbourne, Parkville, Victoria, 3010, Australia -

(a.aien, dshojaei@student.unimelb.edu.au) and (saeidks, abbas.r, ianpw@unimelb.edu.au)

\section{Commission IV, WG IV/1}

KEY WORDS: Land, Development, Analysis, Modelling, Three-dimensional

\begin{abstract}
:
Population growth, urbanization and industrialization place more pressure on land use with the need for increased space. To extend the use and functionality of the land, complex infrastructures are being built, both vertically and horizontally, layered and stacked. These three-dimensional (3D) developments affect the interests (Rights, Restrictions, and Responsibilities (RRRs)) attached to the underlying land. A 3D cadastre will assist in managing the effects of 3D development on a particular extent of land.
\end{abstract}

There are many elements that contribute to developing a 3D cadastre, such as existing of 3D property legislations, 3D DBMS, 3D visualization. However, data modelling is one of the most important elements of a successful 3D cadastre. As architectural models of houses and high rise buildings help their users visualize the final product, 3D cadastre data model supports 3D cadastre users to understand the structure or behavior of the system and has a template that guides them to construct and implement the 3D cadastre.

Many jurisdictions, organizations and software developers have built their own cadastral data model. Land Administration Domain Model (DIS-ISO 19152, The Netherlands) and ePlan (Intergovernmental Committee on Surveying and Mapping, Australia) are examples of existing data models.

The variation between these data models is the result of different attitudes towards cadastres. However, there is a basic common thread among them all. Current cadastral data models use a 2D land-parcel concept and extend it to support 3D requirements. These data models cannot adequately manage and represent the spatial extent of 3D RRRs. Most of the current cadastral data models have been influenced by a very broad understanding of 3D cadastral concepts because better clarity in what needs to be represented and analysed in the cadastre needs to be established.

This paper presents the first version of a 3D Cadastral Data Model (3DCDM_Version 1.0). 3DCDM models both the legal and physical extent of 3D properties and associated interests. The data model extends the traditional cadastral requirements to cover other applications such as urban planning and land valuation and taxation. A demonstration of a test system on the proposed data model is also presented. The test is based on a case study in Victoria, Australia to evaluate the effectiveness of the data model.

\section{INTRODUCTION}

Cadastres as the engine of land administration systems while integrated with spatial data infrastructures (SDI) are required to help manage interests in land and its resources. Until the present, land administration systems have used 2D land parcels as a base to determine, record and disseminate required information regarding land (Kalantari et al., 2008). Land administration systems should be complete, comprehensive, and constant to enable sustainable development. However, they are $2 \mathrm{D}$ and cannot adequately manage and represent the real $3 \mathrm{D}$ world.

The cadastral map should be able to represent and also provide spatial information related to land rights, restrictions and responsibilities (RRRs) not only in 2D space for land parcels, but also in $3 \mathrm{D}$ space for $3 \mathrm{D}$ properties, apartment units and underground infrastructures. Such a system can be described as a 3D cadastre.

3D cadastres would assist management of 3D RRRs. A 3D cadastre should be capable of storing, manipulating, querying, analysis, updating, and supporting the visualisation of 3D land rights, restrictions and responsibilities. 3D cadastral aspects should be considered in any modern system. The legal, institutional and technical aspects of a 3D cadastre provide the framework for its successful development and implementation. However, data modelling is one of the most important elements of a successful 3D cadastre. 3D cadastre data model supports $3 \mathrm{D}$ cadastre users to understand the structure or behaviour of the system and has a template that guides them to construct and implement the $3 \mathrm{D}$ cadastre.

Many jurisdictions have developed their own cadastral data model. Examples of data modelling developments are the core

\footnotetext{
* Corresponding author. This is useful to know for communication with the appropriate person in cases with more than one author.
} 
cadastral data model (Henssen, 1995), FGDC Cadastral Data Content Standard for the National Spatial Data Infrastructure (FGDC, 1996), ArcGIS Parcel Data Model (Meyer, 2001), ePlan (ICSM, 2009), Legal Property Object (Kalantari et al., 2008), and ISO 19152- LADM (ISO/DIS, 2011). The variation between these data models is evidence of the varying expectations of a 3D cadastre. However, there is a basic common thread among them all. Existing cadastral data models have been developed based on the definition of a 2D landparcel, while 2D land-parcel is no longer an efficient spatial component for cadastres.

This paper aims to represent the first version of a developed 3D Cadastral Data Model (3DCDM_Version 1.0). This data model includes 3D cadastral objects and (3D legal and physical objects) and provides a practical framework to model 3D cadastral requirements. Basic components of $2 \mathrm{D}$ cadastral data models and needs for developing a 3D cadastral data model are described in Section 2. Section 3 presents the 3D Cadastral Data Model (3DCDM_Version 1.0) and its components. The 3DCDM_Version 1.0 is tested based on a case study in Victoria, Australia in Section 4. The paper ends with conclusions in Section 5.

\section{CADASTRAL DATA MODELS}

\subsection{D Cadastral Data Models}

The cadastral data models consist of three main components:

1. InterestHolder (Person);

2. Rights, Restrictions, and Responsibilities (RRRs);

3. Land

InterestHolder is a person, group, or an organization that has certain rights (RRRs) over a particular extent of land. Figure 1 shows the relationships between these components of the cadastral data models (Aien et al., 2011a).

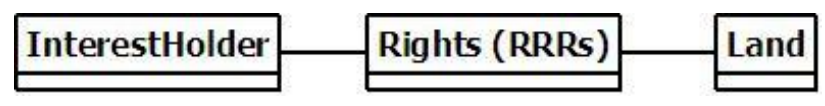

Figure 1. Cadastral Data Model (Oosterom et al., 2006)

\subsection{Problems of Current Cadastral Data Models}

Naturally, the use of land is three dimensional. However, 2D land parcels are being used as a basic building block of the current land administration systems. There are a number of reasons why current cadastral data models still rely on the $2 \mathrm{D}$ land parcels for accommodating 3D data. They are:

- The lack of 3D data collection methods and equipment (lack of information in subdivision plans and architectural maps), and

- $\quad$ Limited 3D storage and representation technologies (3D DBMS, 3D topology, and 3D visualisation specifications).

3D developments changed the characteristics of land parcels. Adding to this complexity were an increasing number of different RRRs (e.g. ownership, easements, noise restriction area, mining lease, planning zone, heritage protection area) are associated with one 2D land parcel.

The 2D land parcel is no longer the appropriate basic spatial component of cadastral models for managing and modelling 3D information; 2D land parcels have been superseded by 3D spatial places. People now own and use volumes of space that can be determined in a 3D coordinate system (Aien et al., 2011b).

\subsection{Needs for Developing a 3D Cadastral Data Model}

The cadastral data models have been developed to support the $3 \mathrm{D}$ cadastre. However, most initiatives are based upon the $2 \mathrm{D}$ cadastral paradigm. In the most cases, a generic spatial unit has been defined to support 3D requirements. This object maintains, for example, 2D land parcels, buildings, and utility network objects (Figure 2). The 2D land parcel object is being used when the model deals with a land parcel, and the building object is being used when a building is being modelled.

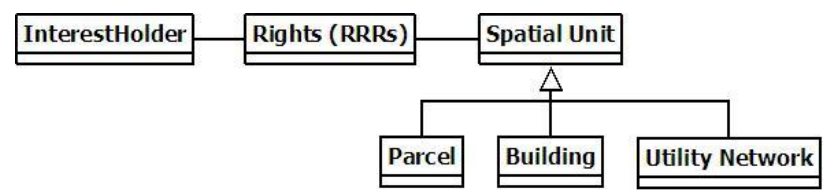

Figure 2. Spatial Package in current cadastral data models (ISO/DIS, 2011)

While a few simple RRRs (such as an easement of way) may be represented on 2D (planar) cadastral paper maps, the diversity and complexity of 3D RRRs requires more than a $2 \mathrm{D}$ cadastral paper map (where 3D features are often incorporated by accompanying descriptive text). That is, 3D RRRs require more than merely grafting of the $3^{\text {rd }}$ dimension information onto a $2 \mathrm{D}$ planar representation. 2D land parcels are not flexible enough to accommodate an increasing number of non-parcel based interests (Bennett et al., 2008; Kalantari et al., 2008). Even after recent advances in storage (database) and visualisation systems, current cadastral systems do not attempt to represent RRRs in digital cadastral databases (DCDB). Consequently, the DCDB does not contain all RRRs (Oosterom et al., 2011).

User expectations are for 3D RRRs to be visualised in a 3D cadastre. However, visualising 3D RRRs alone would not adequately assist management of 3D RRRs (Aien et al., 2011c).

3D objects which represent 3D RRRs are not suitable to manage 3D RRRs. The actual construction of the buildings should be visualised in different details for different land administration functions.

Based on these problems, an attempt has been done to develop a $3 \mathrm{D}$ cadastral data model.

\section{3D CADASTRAL DATA MODEL (3DCDM)}

\subsection{D CADASTRAL DATA MODEL (3DCDM_VERSION 1.0)}

The first version of 3D Cadastral Data Model (3DCDM_Version 1.0) is presented in this section. 3DCDM has seven packages to support the 3D cadastres. They are 3DCDM_InterestHolder, 3DCDM_Propertyobject (PO), 3DCDM_Geometry, 3DCDM_Survey, 3DCDM_SurveyPoints, 3DCDM_SurveyObsevation, and 3DCDM_ExternalSources (Figure 3).

Each package is represented by different colour to better distinguish different packages and to easily identify related specifications of each package. 


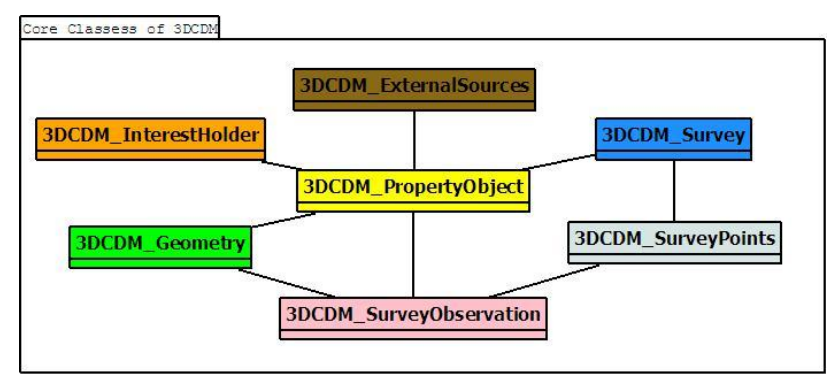

Figure 3. Core classes of 3DCDM

\subsubsection{InterestHolder Package}

The only class in this package is the 3DCDM_InterestHolder class. InterestHolder can be a person, group, or an organization who has certain rights (RRRs) over a particular 3D spatial space (Figure 4).

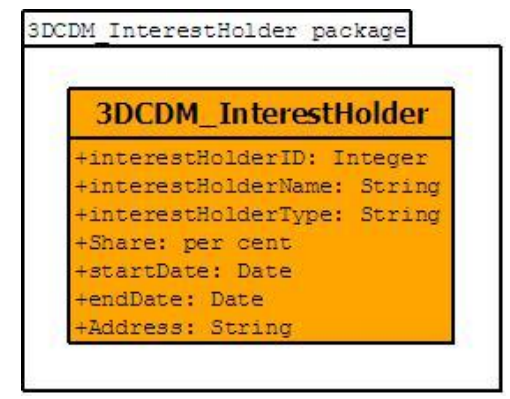

Figure 4: 3DCDM_InterestHolder Package

\subsubsection{PO (Property Object) Package}

The 3D Cadastre Data Model should support both legal and physical objects of a building. Therefore, a 3DCDM_PropertyObject (PO) class has been defined with its two specifications: PO_LegalPropertyObject and PO_PhysicalPropertyObject (Figure 5).

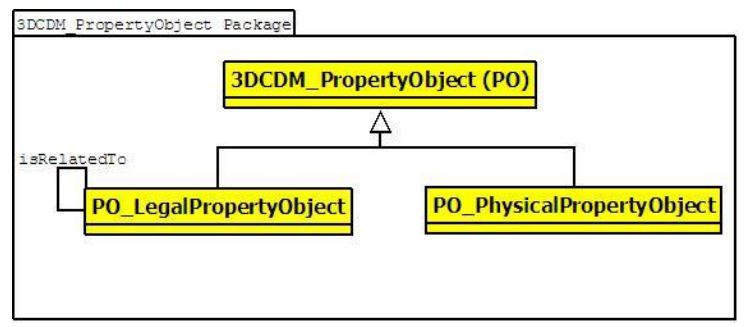

Figure 5. 3DCDM_PropertyObject (PO) package

PO_LegalPropertyObject contains associations to support the legal objects of a building (Figure 6). The PO_LegalPropertyObject has an association with itself to enable the modelling of allocations between existing property objects and the new property objects. All associations are a kind of legal property object (LPO). Different LPOs can create the whole legal object.

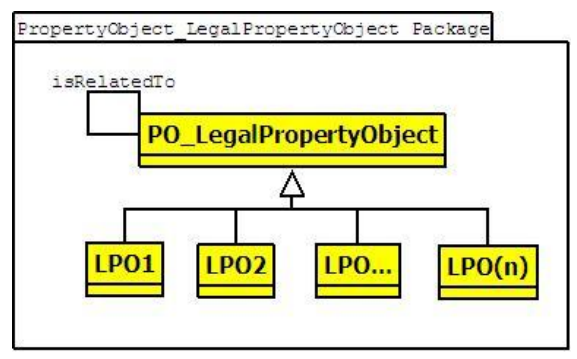

Figure 6. PO_LegalPropertyObject Package
LPO1 can be a Lot. Lot is the name given to a separate piece of land, airspace or building that come into existence when a plan of subdivision is registered in the Australian context (Figure 7). LPO2 can be a common property which is the area of a plan of subdivision which is not included in one of the Lots but is owned and used in common by those Lot owners who are members of the body corporate. It can consist of land, building, air space or an area below the ground (Libbis, 2006).

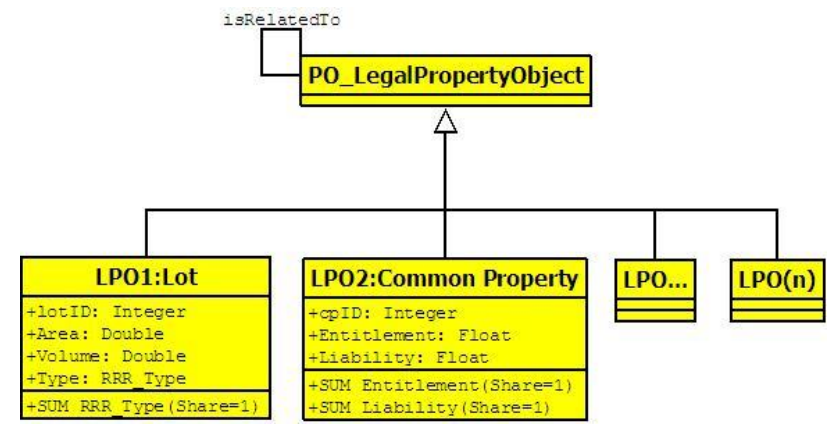

Figure 7. Attributes of PO_LegalPropertyObject

Storey is any level part of a building that has a permanent roof and could be used by people for different purposes. Each storey may contain a unit, its accessories and a utility network. The PO_PhysicalPropertyObject package consists of these objects to model the physical part of a building (Figure 8). Figure 9 describes attributes of PO_PhysicalPropertyObject class.

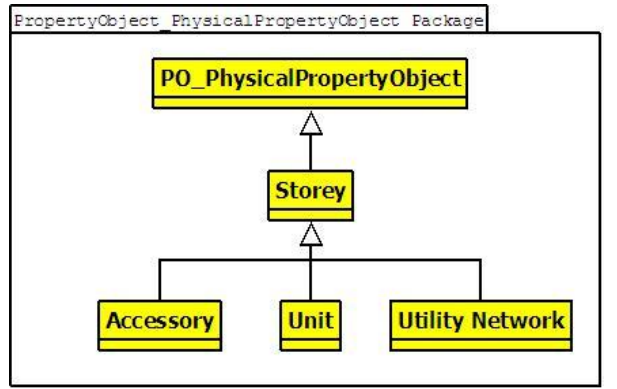

Figure 8. PO_PhysicalPropertyObject Package

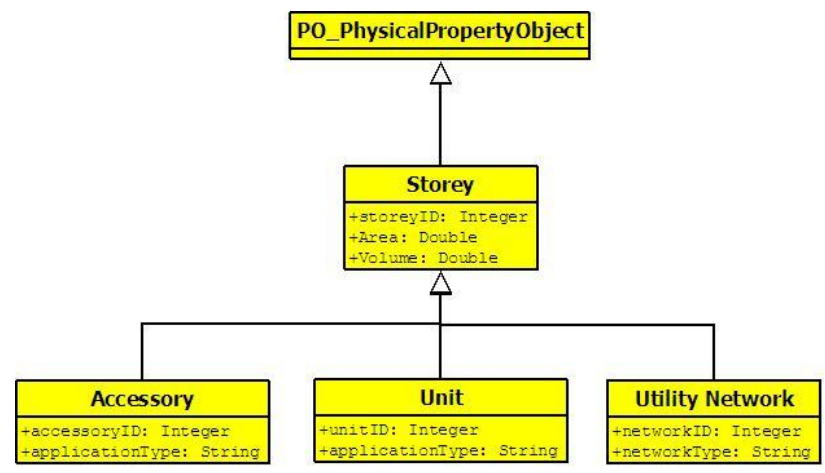

Figure 9. Attributes of PO_PhysicalPropertyObject

\subsubsection{Geometry Package}

This package utilises the geometry model of CityGML to shape the geometry of legal and physical objects. This package consists of primitives to form complexes, composite geometries or aggregates. Point is used for zero-dimensional object,_Curve for one-dimensional, _Surface for two-dimensional, and _Solid for three-dimensional objects (Figure 10). Combination of the primitives (aggregates, complexes or composites) forms more complex objects and provides topology among objects (Gröger et al., 2008). 


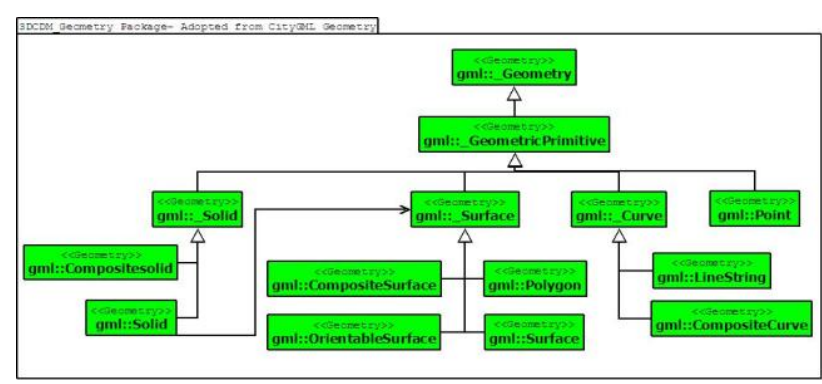

Figure 10.3DCDM_Geometry Package (adopted from CityGML data model)

\subsubsection{Survey Package}

This package contains 4 classes which deal with technical and administrative information of surveying, surveyor, and subdivision plan. They are 3DCDM_Survey, 3DCDM_SurveyMetadata, 3DCDM_CoordinateSystem, and 3DCDM_Surveyor (Figure 11).

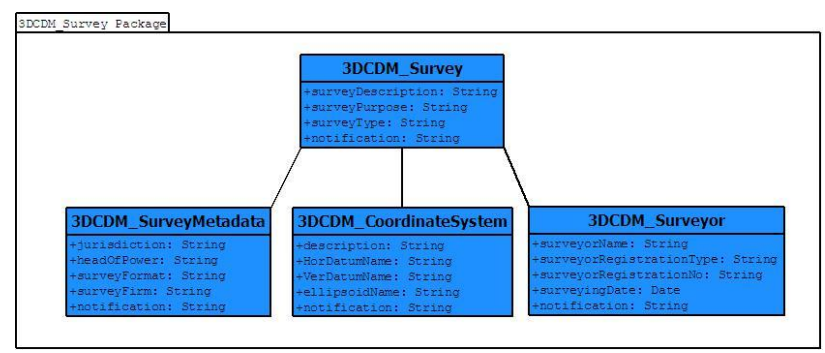

Figure 11.3DCDM_Survey Package

\subsubsection{SurveyPoints Package}

This Package has one 3DCDM_SurveyPoints class to contain the elements related to the survey permanent marks which are placed in the ground by monuments (e.g., pin, peg) for the purpose of being surveyed. Survey points can be $2 \mathrm{D}$ or $3 \mathrm{D}$ (Figure 12).

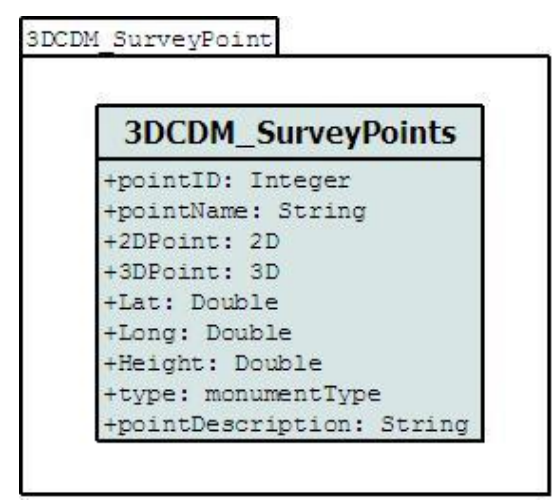

Figure 12.3DCDM_SurveyPoints Package

3.1.6 SurveyObservation Package

The 3DCDM_SurveyObservation package contains 3DCDM_SurveyObservedLine, 3DCDM_SurveyAngle, and 3DCDM_SurveyStation classes to maintain observed data which form a spatial component of the 3DCDM (Figure 13).

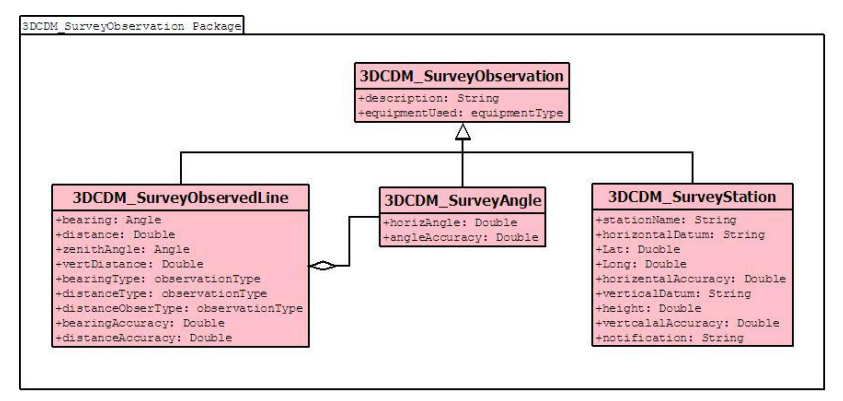

Figure 13.3DCDM_SurveyObservation Package

\subsubsection{ExternalResource Package}

Surveying data and subdivision plans are not detailed enough to guide reconstruction of both legal and physical objects of buildings. In some applications, more detailed information required, which external sources such as architectural and engineering plans can provide. The 3DCDM_ExternalResource package contains only one class to support all different external sources (Figure 14).

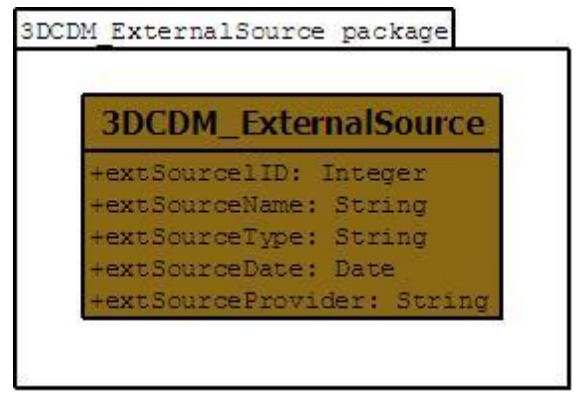

Figure 14.3DCDM_ExternalSource Package

\section{DATA MODEL TEST SUITE}

\subsection{Case study}

In this section, a building subdivision plan has been used as a case study to test and analyse the deficits of 3DCDM_Version 1.0. The case study is a building in Melbourne, Victoria, Australia, which has been subdivided into three Lots. This building has a common property and a party wall as an easement opposed to Lot1 (Figure 15).

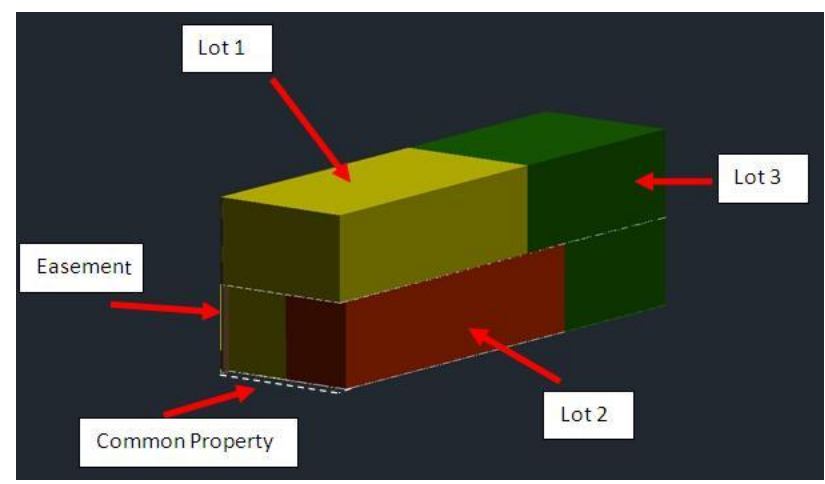

Figure 15. A building with three Lots, a common property, and an easement

3DCDM is a conceptual data model or conceptual schema which is a map of 3D cadastres concepts and their relationship. This data model describes the semantics of the 3D cadastre and represents a series of assertions about its nature. Specifically, it 
describes the things of significance to the $3 \mathrm{D}$ cadastre (entity classes), about which it is inclined to collect information, and characteristics of (attributes) and associations between pairs of those things of significance (relationships).

There are different methods to test a data model. Also, the test can be implemented in different levels. A low level test is to examine basic and core packages and a high level test is to examine whole packages of the data model. Therefore, it is necessary to identify mandatory and optional packages of the data model.

In this section, case study's Lot1 information only is mapped into 3DCDM packages. Each package is represented separately to highlight its information.

Lot1 owned by a natural person (Rob) who has 100 per cent right of use of unit1 of this property (Figure 16). 3DCDM_InterestHolser package consist of personal information about the owner which are important in land administration and land registry.

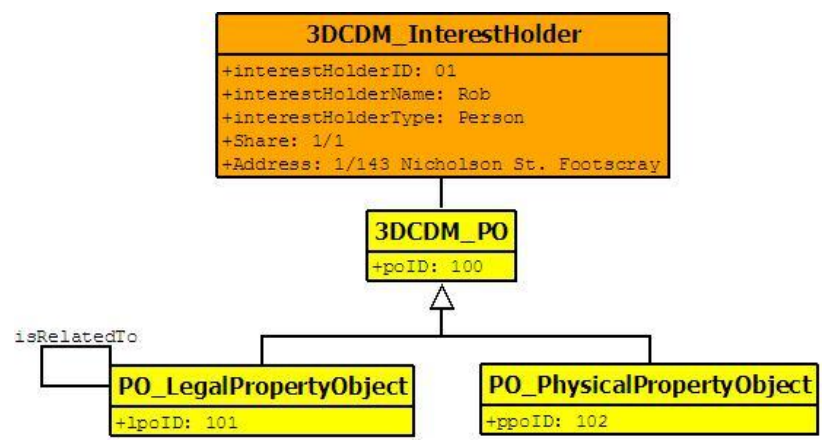

Figure 16. Instance of 3DCDM_InterestHolder Package

PO_LegalPropertyObject association of 3DCDM_PO package contains legal information for Lot1. In this example, Lot1 is a $3 \mathrm{D}$ object with a specific area and volume. Lot 1 is presented as LPO1 in the data model. Ownership type as one of LPO1's attributes indicates type of tenure. Building's common property is presented as LPO2. Owner of Lot1 has entitlement (the share of ownership that a Lot owner has in the common property) and liability (the proportion of the body corporate expenses for which a particular Lot owner) (Figure 17).

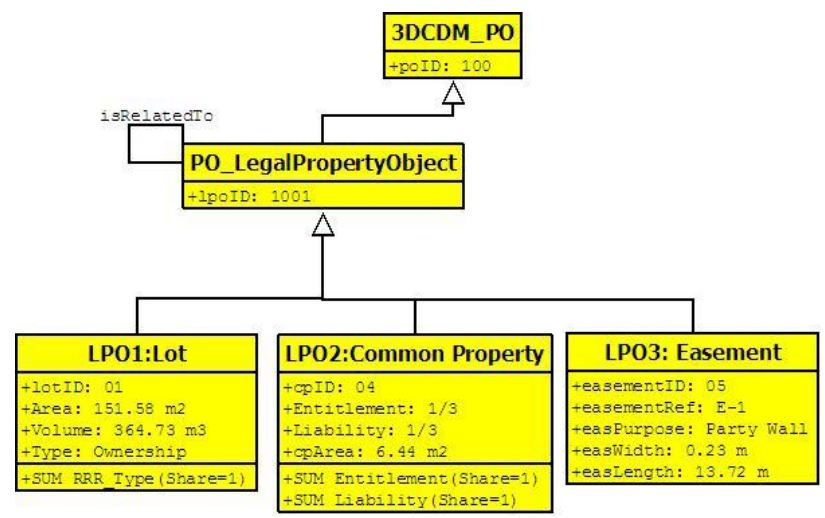

Figure 17. Instance of PO_LegalPropertyObject association of 3DCDM_PO Package

PO_PhysicalPropertyObject association of 3DCDM_PO package have physical information for Lot. Information of this association indicates that Unit1 corresponding with Lot1 has a residential type application and in the same size of its legal object (Figure 18).

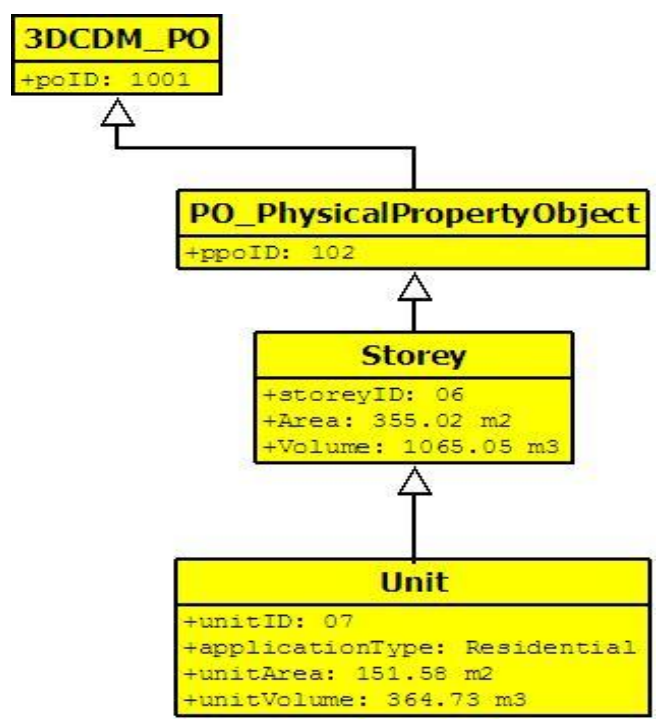

Figure 18. Instance of PO_PhysicalPropertyObject association of 3DCDM_PO Package

In this case study, 3DCDM_Geometry Package utilises surface primitives to form required geometries. gml::_Surface class designed to create two-dimensional objects. To create volumetric objects in this case study gml::_Solid is used (Figure 19).

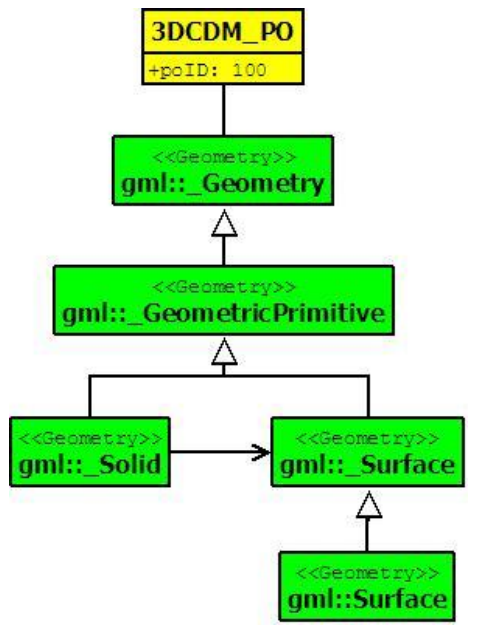

Figure 19. Instance of 3DCDM_Geometry Package

In this example, a registered and licensed surveyor subdivided the property under Subdivision Act 1988. 3DCDM_Survey package contains all information about surveyor and the coordinate system (Figure 20).

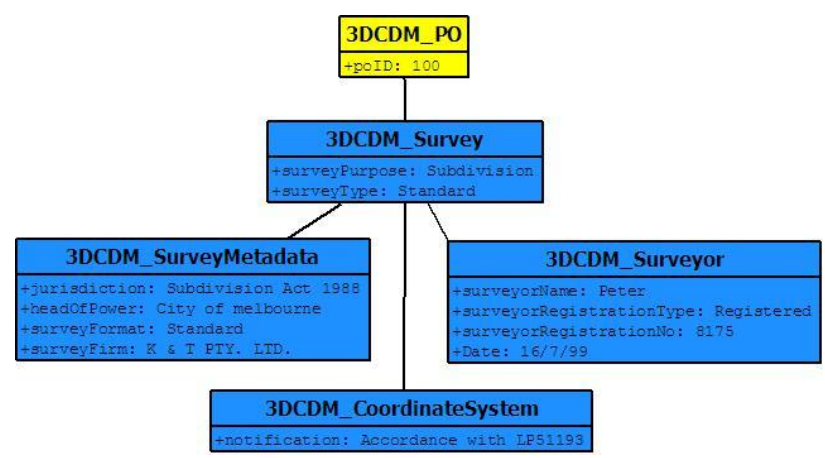

Figure 20. Instance of 3DCDM_Survey Package 
3DCDM_SurveyPoints package indicates that survey points in this example are $2 \mathrm{D}$ and these points do not cover the third dimension (Figure 21).

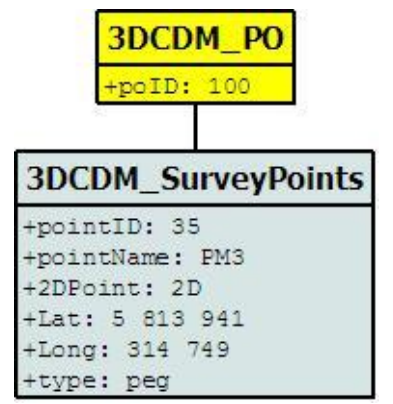

Figure 21. Instance of 3DCDM_SurveyPoints Package

3DCDM_SurveyObservation Package here contains surveying information only for one observation. This information is essential for surveyors to re-subdivide the property and they have to be registered in the land registry (Figure 22).

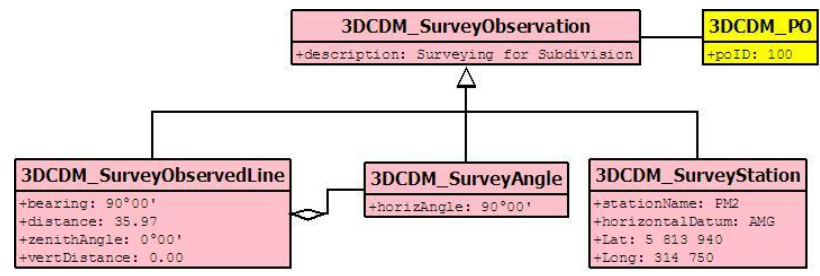

Figure 22. Instance of 3DCDM_SurveyObservation Package

In this case study, no external resources were used to collect extra information. Therefore, 3DCDM_ExternalSource was not implemented in this stage.

3D physical and legal objects of the case study are modelled in 3DCDM. Surveying information and surveying observations are considered in the data model as well. Finally, 3DCDM provides a practical framework to model 3D information of survey plans.

\section{CONCLUSION}

High-rise buildings, underground basements and car parks are examples of increasing three-dimensional land development and land use. However, these systems use outdated two-dimensional cadastral systems. This paper advances the proposition that a comprehensive cadastre must be three-dimensional to properly manage, represent and visualise the spatial extent of 3D land rights, restrictions and responsibilities (3D RRRs).

The paper presents the first version of 3D Cadastral Data Models (3DCDM_Version 1.0). Most of the current cadastral data models have been influenced by a very broad understanding of 3D cadastral concepts while this data model deals with detail information of 3D cadastre.

The first version of 3D Cadastral Data Model (3DCDM_Version 1.0) has been developed to support the 3D cadastre and more city planning applications. This data model has seven packages which support different parts of a 3D cadastral system.

A building subdivision plan was used as a case study to test the data model. This case study contains ordinary elements of a 3D property such as Lot, common property, and easement. Therefore, instance classes of the data model utilised to cover the information of the case study. This simple test shows that how different required information for 3D cadastre can be accommodated in the data model. The next phase of this work will involve piloting and testing the model for more complicated instances.

In the end, it is important to notice that the 3D cadastre will not be required in all areas (e.g. consider isolated rural areas in Australia). This idea may provide clues as to how 3D cadastres will be implemented in practice. 3D cadastral models will need to take this into account: the development of full 3D cadastre will most likely be a staged process. In conclusion, the model presented here can be seen as part of the processes of development.

\section{REFERENCES}

Aien, A., Kalantari, M., Rajabifard, A., Williamson, I. P., \& Bennett, R. 2011a. Advanced Principles of 3D Cadastral Data Modelling. Paper presented at the 2nd International Workshop on $3 D$ Cadastres Proceeding, Delft, The Netherlands.

Aien, A., Rajabifard, A., Kalantari, M., \& Williamson, I. P. 2011b. Aspects of 3D Cadastre- A Case Study in Victoria. Paper presented at the FIG Working Week 2011, Marrakech, Morocco.

Aien, A., Rajabifard, A., Kalantari, M., Williamson, I. P., \& Shojaei, D. 2011c. 3D Cadastre in Victoria, Converting Building plans of Subdivision to LandXML. GIM International, 25(8), 16-21.

Bennett, R., Wallace, J., \& Williamson, I. P. 2008. A toolbox for mapping and managing new interests over land. Survey Review, 40(307), 43-53.

FGDC. 1996. Cadastral Data Content Standard for the National Spatial Data Infrastructure- Version 1.1: NSDI, Standards Working Group, Standards Reference Model.

Gröger, G., Kolbe, T. H., Czerwinski, A., \& Nagel, C. 2008. OpenGIS City Geography Markup Language (CityGML) Encoding Standard-Version: 1.0.0: Open Geospatial Consortium Inc.

Henssen, J. L. G. 1995. Basic Principles of the Main Cadastral Systems in the World. Paper presented at the Seminar Modern Cadastres and Cadastral Innovations, Delft, The Netherlands.

ICSM. (2009). ePlan Model. Retrieved. from http://www.icsm.gov.au/icsm/ePlan/Schema-

1.2/ePlan_Model.pdf \&

http://www.icsm.gov.au/icsm/ePlan/Plan-1.2/index.htm.

ISO/DIS. (2011). ISO/DIS 19152. Draft International Standard (DIS), Geographic Information- Land administration domain model (LADM). Retrieved. from.

Kalantari, M., Rajabifard, A., Wallace, J., \& Williamson, I. P. 2008. Spatially referenced legal property objects. Land Use Policy, 25, 173-183.

Libbis, S. 2006. Subdivisions with the lots. Law Crest.

Meyer, N. V. 2001. ArcGIS Land parcel Data Model: esri.

Oosterom, P. J. M. v., Lemmen, C., Ingvarsson, T., Molen, P. v. d., Ploeger, H. D., Quak, W., et al. 2006. The core cadastral domain model. ScienceDirect, 30, 627-660.

Oosterom, P. v., Stoter, J. E., Ploeger, H. D., Thompson, R., \& Karki, S. (2011). World-wide Inventory of the Status of 3D Cadastres in 2010 and Expectations for 2014. Paper presented at the FIG Working Week 2011, 1822 May 2011. 